\title{
Comparison Study of Clinical Presentation and Surgical Outcome between Children and Adults with Craniopharyngioma: A 22-Year Single-Center Experience in Southern Taiwan
}

\author{
Cheng-Wei Chu', Yu-Feng Su²,3, Ann-Shung Lieu, ${ }^{2,3}$, Chih-Lung Lin ${ }^{2,3}$, Aij-Lie Kwan ${ }^{2,3}$ and Joon-Khim Loh ${ }^{1,2,3 *}$ \\ ${ }^{1}$ Department of Surgery, Kaohsiung Municipal Ta-Tung Hospital, Kaohsiung Medical University, Kaohsiung, Taiwan \\ ${ }^{2}$ Division of Neurosurgery, Department of Surgery, Kaohsiung Medical University Hospital, Kaohsiung, Taiwan \\ ${ }^{3}$ Faculty of Medicine, Graduate Institute of Medicine, College of Medicine, Kaohsiung Medical University, Kaohsiung, Taiwan
}

\begin{abstract}
Background: The differences in clinical presentation and surgical outcome between children and adults with craniopharyngioma have not been well-described and there are few data available for Asian population. The aim of this study is to investigate the differences between paediatric and adult patients with craniopharyngioma at a single medical centre in southern Taiwan.

Methods: The clinical records of 40 patients with craniopharyngioma who were all surgically treated at Kaohsiung Medical University Hospital from January 1990 to December 2012 were reviewed. The patients were divided into two groups based on age: children ( $\leq 20$ years) and adults $(>20$ years). MRI and CT images were obtained pre- and post-operatively. Histopathological examination diagnosed tumors. Statistical analyses were performed to compare the differences in the two groups.

Results: Among the patients, 17 were children and 23 were adults. The children group demonstrated more diagnoses of large or giant tumors $(p<0.001)$, a higher rate of tumors with both solid and cystic composition $(p=0.027)$ as well as adamantinomatous type tumors $(p=0.020)$. The children group also had a higher surgical complication rate of diabetes insipidus $(p=0.023)$.

Conclusions: There are significant differences between children and adults with craniopharyngioma with regard to tumor size, histopathology type of tumor and hormone-related surgical complications. These findings are useful for improving the strategies for managing patients with craniopharyngioma.
\end{abstract}

Keywords: Clinical presentation; Surgical outcome; Craniopharyngioma

\section{Introduction}

Craniopharyngiomas are tumors that are histologically benign in appearance and are generally believed to originate from remnants of Rathke's pouch [1,2]. A histological resemblance has been noted between adamantinomatous craniopharyngiomas and some odontogenic tumors [3]. This similarity has been explained by their common embryonic origin [3]. Based on epithelium pattern, there are two major histological types of craniopharyngiomas: adamantinomatous and papillary types [4]. Some tumors are mixed type. Craniopharyngiomas in nearly all children and about two-thirds of adults are adamantinomatous type [4]. Craniopharyngiomas are typically located in the infundibulo hypophyseal axis in the sella and suprasellar region, but may grow in any direction. Although regarded as benign, they tend to invade into the hypothalamus, pituitary stalk, and optic pathways $[1,5]$. Because of the close anatomical relationship of the tumors to adjacent cerebrovascular structures, surgical resection of the tumor is risky about visual and endocrine dysfunctions as well as the possibility of a major vascular trunk injury [6]. These tumors can be purely cystic, predominantly cystic, purely solid, predominantly solid, or multi-cystic. One published data showed about half of the tumors were predominantly cystic, while less than $4 \%$ of newly diagnosed tumors were purely cystic [7].

Craniopharyngiomas account for $2 \%$ to $5 \%$ of primary intracranial tumors, $1 \%$ to $3 \%$ of paediatric brain tumors, and $6 \%$ to $9 \%$ of primary paediatriccentral nervous system tumors [1,2,8,9]. Craniopharyngiomas could occur in both paediatric and adult groups, even in individuals aged more than 80 years [10]. In the paediatric group, the incidence of craniopharyngiomas peaks at age 5-9 years [11]. For adult group, the Danish study found that the peak incidence occurred in individuals aged 40-44 years [12]. Although craniopharyngiomas could occur in both paediatric and adult groups, the clinical presentation and surgical outcome may differ. Nielsen et al. claimed that there may be differences about how children and adults react to intracranial tumor growth because children's brains were still developing [13]. Furthermore, there had been a perception that the functional outcome of radical surgery is potentially harmful for children [14]. The aim of this study is to investigate the differences between paediatric and adult patients with craniopharyngioma at a single medical centre in southern Taiwan.

\section{Methods}

\section{Patients}

From January 1990 to December 2012, a total of 40 patients (15 males and 25 females) with craniopharyngiomas were treated surgically at Kaohsiung Medical University Hospital in southern Taiwan. MRI

*Corresponding author: Joon-Khim Loh, Department of Surgery, Kaohsiung Municipal Ta-Tung Hospital, Kaohsiung Medical University, Kaohsiung, Taiwan, Tel: 886-7-2911101-8926; Fax: 886-7-2138405; E-mail: jokhlo@kmu.edu.tw

Received June 05, 2017; Accepted June 18, 2017; Published June 21, 2017

Citation: Chu C, Su Y, Lieu A, Lin C, Kwan A, et al. (2017) Comparison Study of Clinical Presentation and Surgical Outcome between Children and Adults with Craniopharyngioma: A 22-Year Single-Center Experience in Southern Taiwan. J Neuro Disord 5: 350. doi:10.4172/2329-6895.1000350

Copyright: () 2017 Chu C, et al. This is an open-access article distributed under the terms of the Creative Commons Attribution License, which permits unrestricted use, distribution, and reproduction in any medium, provided the original author and source are credited. 
and CT images were obtained pre- and post-operatively. The clinical presentations were reviewed on medical charts. Based on ages, the patients were divided into two groups: children (age $\leq 20$ years) and adults (age $>20$ year).

\section{Surgical procedures}

Surgical resection was carried out using either the pterional approach $(n=35)$, trans sphenoidal approach $(n=4)$, or transcallosal approach $(\mathrm{n}=1)$. The surgical techniques had been previously described in detail [15-17].

\section{Radiation therapy}

There were 28 (70\%) patients who received radiation therapy after surgery.

\section{Follow-up}

After surgery, the patients received follow-up monthly. The surgical outcome was divided into 3 groups: 1) Good: no postoperative complications; 2) Fair: minor post-operative complications such as prolonged diabetes insipidus or hemiparesis; 3) Poor: major

\begin{tabular}{|c|c|c|c|c|}
\hline Characteristics & $\begin{array}{l}\text { Total } \\
(n=40)\end{array}$ & $\begin{array}{c}\text { Children } \\
(n=17)\end{array}$ & $\begin{array}{l}\text { Adults } \\
(n=23)\end{array}$ & p-value \\
\hline Sex & & & & 0.283 \\
\hline Males & $15(37.5 \%)$ & $8(47.1 \%)$ & $7(30.4 \%)$ & \\
\hline Females & $25(62.5 \%)$ & $9(52.9 \%)$ & $16(69.6 \%)$ & \\
\hline Age & & & & NA \\
\hline $0-10$ yrs & $6(15.0 \%)$ & $6(35.3 \%)$ & $0(0 \%)$ & \\
\hline $11-20$ yrs & $11(27.5 \%)$ & $11(64.7 \%)$ & $0(0 \%)$ & \\
\hline $21-30$ yrs & $9(22.5 \%)$ & $0(0 \%)$ & $9(39.2 \%)$ & \\
\hline $31-40$ yrs & $3(7.5 \%)$ & $0(0 \%)$ & $3(13.0 \%)$ & \\
\hline $41-50$ yrs & $3(7.5 \%)$ & $0(0 \%)$ & $3(13.0 \%)$ & \\
\hline $51-60$ yrs & $5(12.5 \%)$ & $0(0 \%)$ & $5(21.8 \%)$ & \\
\hline $61-70$ yrs & $2(5.0 \%)$ & $0(0 \%)$ & $2(8.7 \%)$ & \\
\hline$>70 y r s$ & $1(2.5 \%)$ & $0(0 \%)$ & $1(4.3 \%)$ & \\
\hline \multicolumn{5}{|l|}{ Clinical presentation } \\
\hline Visual problem & $32(80 \%)$ & $13(76.5 \%)$ & $19(82.6 \%)$ & 0.702 \\
\hline Headache & $26(65.0 \%)$ & $12(70.6 \%)$ & $14(60.9 \%)$ & 0.739 \\
\hline Stunted growth & $10(25.0 \%)$ & $9(52.9 \%)$ & $1(4.3 \%)$ & $0.001^{\star}$ \\
\hline Polyuria & $9(22.5 \%)$ & $5(29.4 \%)$ & $4(17.4 \%)$ & 0.456 \\
\hline Changes in mentation & $6(15.0 \%)$ & $2(11.8 \%)$ & $4(17.4 \%)$ & 1.000 \\
\hline \multicolumn{5}{|l|}{ Calcification } \\
\hline Skull & $26(65.0 \%)$ & $8(47.1 \%)$ & $18(78.3 \%)$ & $0.041^{\star}$ \\
\hline CT & $14(35.0 \%)$ & $9(52.9 \%)$ & $5(21.7 \%)$ & 0.749 \\
\hline Composition & & & & 0.074 \\
\hline Solid & $5(12.8 \%)$ & $1(5.9 \%)$ & $4(18.2 \%)$ & 0.363 \\
\hline Cystic & $13(32.5 \%)$ & $3(17.6 \%)$ & $10(43.5 \%)$ & 0.103 \\
\hline Solid \& cystic & $22(55.0 \%)$ & $13(76.5 \%)$ & $9(39.1 \%)$ & $0.027^{*}$ \\
\hline Size of tumor & & & & $<.001^{*}$ \\
\hline Small $(<2 \mathrm{~cm})$ & $5(12.5 \%)$ & $1(5.9 \%)$ & $4(17.4 \%)$ & \\
\hline Moderate $(2-4 \mathrm{~cm})$ & $16(40.0 \%)$ & $3(17.6 \%)$ & $13(56.5 \%)$ & \\
\hline Large $(4-6 \mathrm{~cm})$ & $14(35.0 \%)$ & $8(47.1 \%)$ & $6(26.1 \%)$ & \\
\hline Giant (>6cm) & $5(12.5 \%)$ & $5(29.4 \%)$ & $0(0 \%)$ & \\
\hline Tumor histopathology & & & & $0.010^{*}$ \\
\hline Adamantinomatous & $27(67.5 \%)$ & $15(88.2 \%)$ & $12(52.2 \%)$ & \\
\hline Squamous papillary & $9(34.8 \%)$ & $0(0 \%)$ & $9(34.8 \%)$ & \\
\hline Mixed & $4(10 \%)$ & $2(11.8 \%)$ & $2(8.7 \%)$ & \\
\hline
\end{tabular}

Table 1: Comparison of characteristics between children and adults. post-operative complications such as permanent diabetes insipidus, hemiplegia or mortality.

\section{Statistical analysis}

Data for surgical profiles and pathology characteristics were presented as $\mathrm{n}(\%)$. Differences between children and adults were compared using Pearson chi-square or Fisher's exact test if any cell number was less than 5 . All statistical assessments were two-tailed and considered significant at $p<0.05$. Statistical analyses were performed using SPSS 18.0 statistics software (SPSS Inc, Chicago, IL, USA).

\section{Results}

A total of 40 patients were enrolled in this study. Among these 40 patients, 17 were children (age $\leq 20$ years; 8 males and 9 females) and 23 were adults (age $>20$ years; 7 males and 16 females). The characteristics of these 40 patients are presented in Table 1. At clinical presentation, children had a higher rate of stunted growth than adults ( $52.9 \%$ vs. $4.3 \% ; p=0.001$ ). About calcification, adults had a higher rate of calcification in the skull than children $(78.3 \%$ vs. $47.1 \%, p=0.041)$. Children had a higher rate of having tumors with both solid and cystic composition than adults ( $76.5 \%$ vs. $39.1 \%, p=0.027)$. With respect to tumor size, more than $70 \%$ of children were diagnosed with large or giant tumors whereas adults were frequently diagnosed with small or moderate tumors $(p<0.001)$. No adult was found having a giant tumor. The tumor histopathology results were significantly different between children and adults $(p=0.010)$. Children had a higher rate of adamantinomatous type tumors than adults $(p=0.020$, not shown in the table). Nine squamous papillary cases were observed in adults while none in children. Table 2 presents the results of the comparison between children and adults about the surgical procedures, postoperative complications, and follow-up outcome. Children had a higher rate of post-operative temporary diabetes insipidus than adults. (41.2\% vs. $8.7 \%$; $p=0.023$ ). No significant differences were observed in surgical procedures or hydrocephalus requiring shunt placement between children and adults. The follow-up prognosis for 30 (75\%) patients was good, for $6(15 \%)$ fair, and for $4(10 \%)$ poor with late mortality. A total of $28(70 \%)$ patients received radiation therapy after surgery. There were 6 patients ( 5 children and 1 adult) having tumor recurrence. Table 3 presents the results of comparison of clinical characteristics among different histopathology types in children and adults.

Figure 1 shows 3 examples of H\&E staining of adamantinomatous, papillary, and adamantinomatous plus papillary (mixed type) craniopharyngiomas. Figure 2 demonstrates a post-operative complication from a 10-year-old male patient with a giant adamantinomatous craniopharyngioma. In Figure 3, MRI scans reveal a 11-year-old male patient with a giant craniopharyngioma and the total removal of the tumor was performed.

\section{Discussion}

The differences in clinical presentation and surgical outcome between children and adults with craniopharyngioma have not been well-described and there are few data available for Asian population. The aim of this study is to investigate the differences between paediatric and adult patients with craniopharyngioma at a single medical centre in southern Taiwan. Our study demonstrates some differences such as that children tended to have stunted growth, large or giant tumors with solid and cystic composition, and adamantinomatous type histopathology. Post-operative diabetes insipidus was more often seen in children group. Karavitaki et al. compared the symptoms between 41 children and 78 adults with craniopharyngioma and found that a significantly higher 


\begin{tabular}{|c|c|c|c|c|}
\hline & $\begin{array}{l}\text { Total } \\
(n=40)\end{array}$ & $\begin{array}{l}\text { Children } \\
(\mathrm{n}=17)\end{array}$ & $\begin{array}{l}\text { Adults } \\
(\mathrm{n}=23)\end{array}$ & $p$-value \\
\hline \multicolumn{5}{|l|}{ Surgical procedures } \\
\hline \multicolumn{5}{|l|}{ Surgical approach } \\
\hline Pterional & $35(84.7 \%)$ & $15(88.2 \%)$ & $20(87.0 \%)$ & 1.000 \\
\hline Transsphenoidal & $4(10.0 \%)$ & $1(5.9 \%)$ & $3(13.0 \%)$ & 0.624 \\
\hline Transcallosal & $1(2.5 \%)$ & $1(5.9 \%)$ & $0(0 \%)$ & 0.425 \\
\hline Treatment types & & & & 0.523 \\
\hline Gross total & $20(50.0 \%)$ & $7(41.2 \%)$ & $13(56.5 \%)$ & \\
\hline Subtotal & $20(50.0 \%)$ & $10(58.8 \%)$ & $10(43.5 \%)$ & \\
\hline \multicolumn{5}{|c|}{ Post-operative complications } \\
\hline \multicolumn{5}{|l|}{ Diabetes insipidus } \\
\hline Temporary & $9(22.5 \%)$ & $7(41.2 \%)$ & $2(8.7 \%)$ & $0.023^{*}$ \\
\hline Permanent & $2(5.0 \%)$ & $2(11.8 \%)$ & $0(0 \%)$ & 0.174 \\
\hline \multicolumn{5}{|l|}{ Chronic subdural } \\
\hline hematoma & $3(7.5 \%)$ & $3(17.6 \%)$ & $0(0 \%)$ & 0.069 \\
\hline Convulsion & $5(12.5 \%)$ & $2(11.8 \%)$ & $3(13.0 \%)$ & 1.000 \\
\hline Hemorrhage & $1(2.5 \%)$ & $1(5.9 \%)$ & $0(0 \%)$ & 0.425 \\
\hline GI bleeding & $1(2.5 \%)$ & $0(0 \%)$ & $1(4.3 \%)$ & 1.000 \\
\hline \multicolumn{5}{|c|}{$\begin{array}{l}\text { Hydrocephalus requiring } \\
\text { shunt placement }\end{array}$} \\
\hline Hydrocephalus & $22(55.0 \%)$ & $12(70.6 \%)$ & $10(43.5 \%)$ & 0.116 \\
\hline V-P shunt & $11(27.5 \%)$ & $6(35.3 \%)$ & $5(21.7 \%)$ & 0.477 \\
\hline \multicolumn{5}{|l|}{ Follow-up } \\
\hline Prognosis & & & & 0.141 \\
\hline Good & $30(75.0 \%)$ & $11(64.7 \%)$ & $19(82.6 \%)$ & \\
\hline Fair & $6(15.0 \%)$ & $3(17.6 \%)$ & $3(13.0 \%)$ & \\
\hline Poor & $4(10.0 \%)$ & $3(17.6 \%)$ & $1(4.3 \%)$ & \\
\hline Receiving radiation & $28(70.0 \%)$ & $14(82.4 \%)$ & $14(60.9 \%)$ & 0.179 \\
\hline Recurrence & $6(15.0 \%)$ & $5(29.4 \%)$ & $1(4.3 \%)$ & 0.067 \\
\hline
\end{tabular}

Table 2: Comparison of the surgical procedures, treatment types, post-operative complications, and follow-up outcomes between children and adults. proportion of children had headache, nausea/vomiting, cranial nerve palsy, papilloedema, and hydrocephalus [18]. Nielsen et al. compared 39 children with 150 adults and reported that children had a higher frequency of acute symptoms, radiologic evidence of hydrocephalus, and ophthalmoplegia while adults had a higher incidence of visual field reduction [13]. It should be noted that in these 2 studies, the children were aged $<15$ years and the adults aged $\geq 15$ years whereas in our study children were aged $\leq 20$ years and adults aged $>20$ years because the civil law in Taiwan provides that adults are people over 20 years of age. 5 of 17 patients in children group are between 15-20 years old. We did not find any significant differences in frequency of headache or visual problems at presentation between children and adults. The only significant difference we found at clinical presentation was that a significantly higher percentage of children had stunted growth Differences in results between the 2 previous studies and ours may be mainly due to racial variations.

Many studies had compared some histopathology characteristics between children and adults with craniopharyngioma about histological type, tumor composition, and tumor size. It has been clearly shown that children rarely have the papillary type tumor. Gautier reported that 61 children had the adamantinomatous type tumors compared with only 3 other children with the papillary type ones [2]. In our study, none of the children had the papillary type tumor. We also found that children more often had tumors with both solid and cystic composition. Sorva et al. reported that adults more often have solid tumors while children more frequently had tumors with calcification [19]. Likewise, Mortini et al. reported that a significantly higher proportion of children had calcified tumors [9]. It has been consistently reported that craniopharyngiomas are larger in children than in adults [19]. Nielsen et al. found that the mean tumor diameter in children was $39.3 \mathrm{~mm}$ compared with $26.5 \mathrm{~mm}$ in adults [13]. In our study, we found that a significantly higher percentage of children have large or giant tumors. An important finding of our

\begin{tabular}{|c|c|c|c|c|c|c|c|}
\hline \multirow[b]{2}{*}{ Variables } & \multicolumn{3}{|c|}{ Children } & \multicolumn{4}{|c|}{ Adults } \\
\hline & Adamantinomatous $(n=15)$ & Mixed $(n=2)$ & p-value & Adamantinomatous $(n=12)$ & Squamous-papillary $(n=9)$ & Mixed(n=2) & p-value \\
\hline Sex & & & 1.000 & & & & 0.189 \\
\hline Males & $8(53.3 \%)$ & $1(50 \%)$ & & $6(50 \%)$ & $1(12.5 \%)$ & $2(100 \%)$ & \\
\hline Females & $7(46.7 \%)$ & $1(50 \%)$ & & $6(50 \%)$ & $7(87.5 \%)$ & $0(0 \%)$ & \\
\hline Age & & & 1.000 & & & & 0.561 \\
\hline $0-10 \mathrm{yrs}$ & $5(33.3 \%)$ & $1(50 \%)$ & & & & & \\
\hline $11-20 \mathrm{yrs}$ & $10(66.7 \%)$ & $1(50 \%)$ & & & & & \\
\hline $21-30 \mathrm{yrs}$ & & & & $4(33.3 \%)$ & $4(50 \%)$ & $1(50 \%)$ & \\
\hline $31-40 \mathrm{yrs}$ & & & & $1(8.3 \%)$ & $1(12.5 \%)$ & $0(0 \%)$ & \\
\hline $41-50 \mathrm{yrs}$ & & & & $3(25.0 \%)$ & $0(0 \%)$ & $0(0 \%)$ & \\
\hline $51-60 \mathrm{yrs}$ & & & & $3(25.0 \%)$ & $2(25 \%)$ & $0(0 \%)$ & \\
\hline $61-70$ yrs & & & & $0(0 \%)$ & $1(12.5 \%)$ & $1(50 \%)$ & \\
\hline$>70 \mathrm{yrs}$ & & & & $1(8.3 \%)$ & $0(0 \%)$ & $0(0 \%)$ & \\
\hline Size of tumor $(\mathrm{cm})$ & & & 1.000 & & & & 0.565 \\
\hline Small $(<2)$ & $1(6.7 \%)$ & $0(0 \%)$ & & $3(25 \%)$ & $1(12.5 \%)$ & $0(0 \%)$ & \\
\hline Moderate (2-4) & $3(20 \%)$ & $0(0 \%)$ & & $5(41.7 \%)$ & $6(75.0 \%)$ & $1(50 \%)$ & \\
\hline Large (4-6) & $7(46.7 \%)$ & $1(50 \%)$ & & $4(33.3 \%)$ & $1(12.5 \%)$ & $1(50 \%)$ & \\
\hline Giant (>6) & $4(26.7 \%)$ & $1(50 \%)$ & & $0(0 \%)$ & $0(0 \%)$ & $0(0 \%)$ & \\
\hline \multicolumn{8}{|l|}{ Follow-up } \\
\hline Prognosis & & & 0.596 & & & & 0.069 \\
\hline Good & $10(66.7 \%)$ & $1(50 \%)$ & & $9(75 \%)$ & $9(100 \%)$ & $1(50 \%)$ & \\
\hline Fair & $2(13.3 \%)$ & $1(50 \%)$ & & $3(25 \%)$ & $0(0 \%)$ & $0(0 \%)$ & \\
\hline Late mortality & $3(20.0 \%)$ & $0(0 \%)$ & & $0(0 \%)$ & $0(0 \%)$ & $1(50 \%)$ & \\
\hline Recurrence & $4(26.7 \%)$ & $1(50 \%)$ & 0.515 & $0(0 \%)$ & $1(12.5 \%)$ & $0(0 \%)$ & 0.456 \\
\hline
\end{tabular}

Note: Data are presented as $\mathrm{n}(\%)$ by tumor histopathology for children and adults, separately. Difference among tumor histopathology was compared using Fisher's exact test.

No significant association with tumor histopathology was observed in children or adults $(\mathrm{P}<0.05)$

Table 3: Comparison of clinical characteristics among different histopathology types in children and adults. 

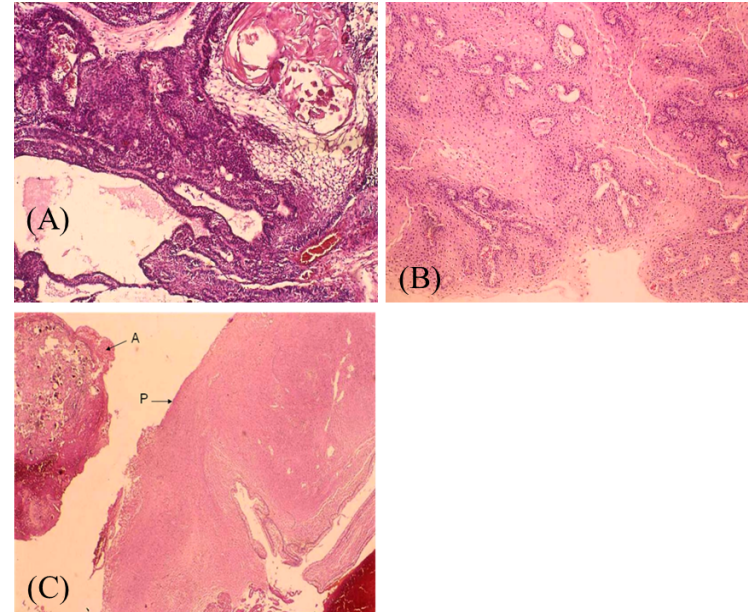

Figure 1: Examples of immunohistochemical staining. (A) Adamantinomatous craniopharyngioma. Loosely cohesive squamous cells surrounded by peripherally palisading cells. A squamous nodule (wet keratin) (arrowheads) is observed (H\&E x100). (B) Papillary craniopharyngioma. Well-differentiated squamous epithelium lining loose connective tissue (H\&E x100). (C) Adamantinomatous $(A)+$ Papillary $(P)$ craniopharyngioma (mixed type) (H\&E x40).

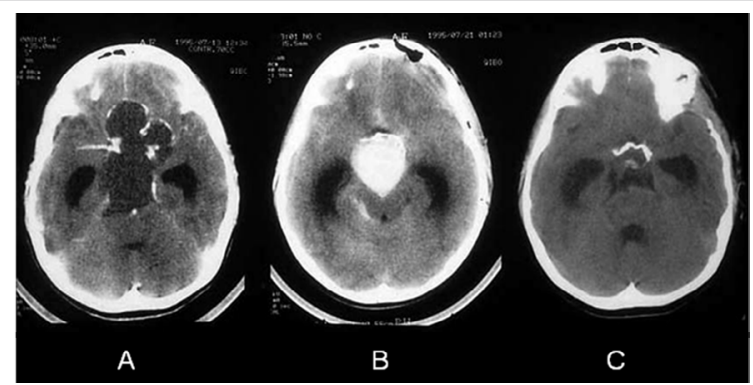

Figure 2: CT scan images showing a post-operative complication from a 10-year-old male patient with a giant adamantinomatous craniopharyngioma. (A) A giant craniopharyngioma. (B) Post-operative suprasellar hemorrhage. (C) Status post total hematoma removal.

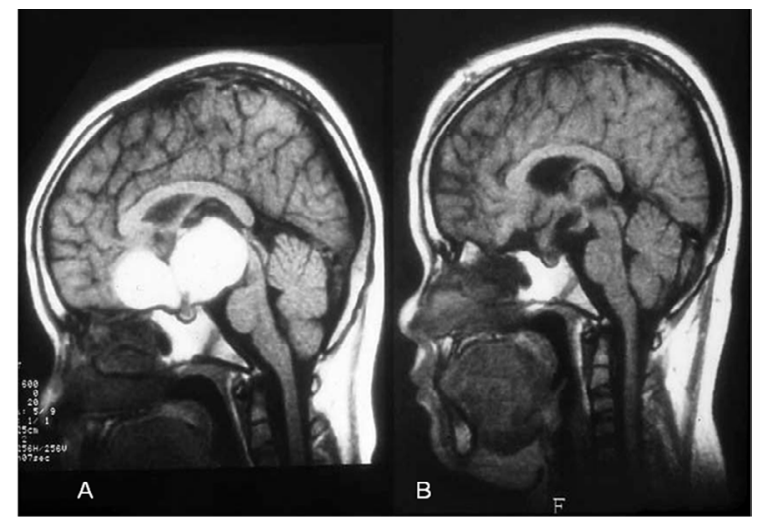

Figure 3: MRI images of a representative case from an 11-year-old male patient. (A) A giant craniopharyngioma. (B) Status post total removal of tumor via pterional approach.

study was that children had more frequent post-operative complication of diabetes insipidus than adults. Gautier et al. found that patients with early onset disease (age $<10$ years) had a significantly higher morbidity rate [2]. Lower awareness of increased intracranial pressure (IICP) might facilitate the brain tumor progression. Some IICP symptoms such as headache and nausea in children group might be considered as non-specific cold or gastrointestinal disturbances. Since children tend to have larger tumors which potentially lead to diabetes insipidus because of mass effect and are more difficult to be totally removed, it would be expected that post-operative morbidity would be greater in children. On the other hand, we did not find any significant difference between children and adults in the frequency of chronic subdural hematoma, convulsion, haemorrhage or gastrointestinal bleeding. Our study has several limitations. It was a retrospective study in design. The sample size was small with 40 patients being included. However, the number of children $(n=17)$ and adults $(n=23)$ was similar with no gender predominance $(\mathrm{p}=0.283)$. We defined children as patients aged $<20$ years but some other studies used different definitions making the further comparison difficult. Larger studies are needed to investigate the differences between children and adults with craniopharyngioma and the age definition of these groups need to be standardized. Also, more studies on Asian population are needed to determine whether there are any racial differences with this disease.

\section{Conclusion}

There are significant differences between children and adults with craniopharyngioma about tumor size, histopathology type of tumor and hormone-related surgical complications. These findings are useful for improving the strategies for managing patients with craniopharyngioma.

\section{References}

1. Clark AJ, Cage TA, Aranda D, Parsa AT, Auguste KI, et al. (2012) Treatmentrelated morbidity and the management of pediatric craniopharyngioma: A systematic review. J Neurosurg Pediatr 10: 293-301.

2. Gautier A, Godbout A, Grosheny C, Tejedor I, Coudert M, et al. (2012) Markers of recurrence and long-term morbidity in craniopharyngioma: A systematic analysis of 171 patients. J Clin Endocrinol Metab 97: 1258-1267.

3. Sekine S, Takata T, Shibata T, Mori M, Morishita Y, et al. (2004) Expression of enamel proteins and LEF1 in adamantinomatous craniopharyngioma: evidence for its odontogenic epithelial differentiation. Histopathology 45: 573-579.

4. Tavanger SM, Larijani B, Mahta A, Hosseini SMA, Mehrazine M, et al. (2004) Craniopharyngioma: A clinicopathological study of 141 cases. Endocr Pathol 4: 339-344.

5. Zacharia BE, Bruce SS, Goldstein H, Malone HR, Neugut Al, et al. (2012) Incidence, treatment and survival of patients with craniopharyngioma in the surveillance, epidemiology and end results program. Neuro Oncol 14: 10701078.

6. Caldarelli M, Massimi L, Tamburrini G, Cappa M, Di Rocco C (2005) Long-term results of the surgical treatment of craniopharyngioma: The experience at the Policlinico Gemelli, Catholic University, Rome. Childs Nerv Syst 21: 747-757.

7. Fahlbusch R, Honegger J, Paulus W, Huk W, Buchfelder M (1999) Surgical treatment of craniopharyngiomas: Experience with 168 patients. J Neurosurg 90: $237-250$.

8. Hukin J, Visser J, Sargent M, Goddard K, Fryer C, et al. (2005) Childhood craniopharygioma: Vancouver experience. Childs Nerv Syst 21: 758-765.

9. Mortini P, Losa M, Pozzobon G, Barzaghi R, Riva M, et al. (2011) Neurosurgical treatment of craniopharyngioma in adults and children: Early and long-term results in a large case series. J Neurosurg 114: 1350-1359.

10. Laijani B, Bastanhagh MH, Pajouhi M, Kargar Shadab F, Vasigh A, et al. (2004) Presentation and outcome of 93 cases on craniopharyngioma. Eur J Cancer Care 13: 11-15.

11. Tomita T, Bowman RM (2005) Craniopharyngiomas in children: Surgical experience at Children's Memorial Hospital. Childs Nerv Sys 21: 729-746.

12. Nielsen EH, Feldt-Rasmussen U, Poulsgaard L, Kristensen LO, Astrup J, et al. (2011) Incidence of craniopharyngioma in Denmark $(n=189)$ and estimated world incidence of craniopharyngioma in children and adults. J Neurooncol 104: 755-763.

13. Nielsen EH, Jørgensen JO, Bjerre P, Andersen M, Andersen C, et al. (2013) 
Citation: Chu C, Su Y, Lieu A, Lin C, Kwan A, et al. (2017) Comparison Study of Clinical Presentation and Surgical Outcome between Children and Adults with Craniopharyngioma: A 22-Year Single-Center Experience in Southern Taiwan. J Neurol Disord 5: 350. doi:10.4172/2329-6895.1000350

Acute presentation of craniopharyngioma in children and adults in a Danish national cohort. Pituitary 16: 528-535.

14. Van Effenterre R, Boch AL (2002) Craniopharyngioma in adults and children: A study of 122 surgical cases. J Neurosurg 97: 3-11.

15. Alleyne CH Jr, Barrow DL, Oyesiku NM (2002) Combined transsphenoidal and pterional craniotomy approach to giant pituitary tumors. Surg Neurol 57: 380-390.

16. Mortini P, Giovanelli M (2002) Transcranial approaches to pituitary tumors. Oper Tech Neurosurg 5: 239-251.
17. Mortini P, Losa M, Barzaghi R, Boari N, Giovanelli M (2005) Results of transsphenoidal surgery in a large series of patients with pituitary adenoma. Neurosurgery 56: 1222-1233.

18. Karavitaki N, Brufani C, Warner JT, Adams CB, Richards P, et al. (2005) Craniopharyngiomas in children and adults: Systematic analysis of 121 cases with long-term follow-up. Clin Endocrinol 62: 397-409.

19. Sorva R, Jääskinen J, Heiskanen O (1987) Craniopharyngioma in children and adults. Correlations between radiological and clinical manifestations. Acta Neurochir 89: 3-9. 